\title{
EFFECTS OF DENTAL IMPLANT LENGTH AND BONE QUALITY ON BIOMECHANICAL RESPONSES IN BONE AROUND IMPLANTS: A 3-D NON-LINEAR FINITE ELEMENT ANALYSIS
}

\author{
Chun-Li Lin ${ }^{1}$, Yu-Chan KuO², Ting-Sheng Lin ${ }^{3}$ \\ ${ }^{1}$ Department of Mechanical Engineering, Graduate Institute of Medical Mechatronic, \\ Chang Gung University, Tao-yuan, Taiwan \\ ${ }^{2}$ Graduate Institute of Medical Mechatronic, Chang Gung University, Tao-yuan, Taiwan \\ ${ }^{3}$ Institute of Biomedical Engineering, National Cheng-Kung University, Tainan, Taiwan
}

\begin{abstract}
The aim of this study was to evaluate the influence of implant length and bone quality on the biomechanical aspects in alveolar bone and dental implant using non-linear finite element analysis. Two fixture lengths (8 and $13 \mathrm{~mm}$ ) of Frialit-2 root-form titanium implants were buried in 4 types of bone modeled by varying the elastic modulus for cancellous bone. Contact elements were used to simulate the realistic interface fixation within the implant system. Axial and lateral (buccolingual) loadings were applied at the top of the abutment to simulate the occlusal forces. The simulated results indicated that the maximum strain values of cortical and cancellous bone increased with lower bone density. In addition, the variations of cortical bony strains between $13 \mathrm{~mm}$ and $8 \mathrm{~mm}$ long implants were not significantly as a results of the same contact areas between implant fixture and cortical bone were found for different implant lengths. Lateral occlusal forces significantly increased the bone strain values when compared with axial occlusal forces regardless of the implant lengths and bone qualities. Loading conditions were found as the most important factor than bone qualities and implant lengths affecting the biomechanical aspects for alveolar bone and implant systems. The simulated results implied that further understanding of the role of occlusal adjustment influencing the loading directions are needed and might affect the long-term success of an implant system.
\end{abstract}

Biomed Eng Appl Basis Comm, 2005(February); 17: 44-49.

Keywords: biomechanics, contact, dental implant, finite element analysis, bone density

\section{INTRODUCTION}

Osseointegrated dental implants has been accepted

Received: June 9, 2004; Accepted: Jan 28, 2005

Correspondence: Chun-Li Lin, Assistant Professor

Department of Mechanical Engineering,

Graduate Institute of Medical Mechatronic,

Chang Gung University, Tao-yuan, Taiwan

E-mail: cllin@mail.cgu.edu.tw as one of the major treatment concepts for restoring completely and partially edentulism patients over the last three decades [1-2]. Despite the high success rates reported by a vast number of literatures, timedependent marginal bone resorption around implants is still unavoidable. Clinical studies have reported significant marginal bone loss around the implant neck inducing the implant to fail, bone loss occurrence was often attributed to oral hygiene and biomechanical factors [2, 4-6]. The biomechanical aspects can be related mostly to the implant design (eg, length, 
diameter, shape and material property) and to the patient physiological condition (eg, bone density, occlusal force and medical condition).

In all incidences of functional loading with implants, the occlusal forces are transferred to the bone-implant interface via an implant-supported prosthesis. The process and the consequences of force transmission into supporting bone depends on the nature of applied force (amplitude, direction and frequency), the design of implants (shape, length and diameter), the biological of the bone-implant interface, the reaction of bone tissue to the mechanical environment created by loading of the implant. To date, some of the implant design factors affected the force transfer characteristics to surrounding bone has been recognized and proposed in the literatures. Albrektsson et al. indicated that greater bone loss was found around cylinder implants when compared that of the screw-type implants and assumed that an inadvertent load transmission from the cylindrical implants to the surrounding bone could be a possible explanation of this finding [7]. Using finite element analysis (FEA), Rieger et al. showed that tapered implants were better than cylindrical implants to avoid 'punching' stresses, and as a choice of retentive elements [8]. However, there has been insufficient research focusing on the pattern of load transfer and the failures with the effect of implant length that correlated with the force transmission area of implantbone interface.

Another of the significant factors that affect the outcome of the implant treatment is the quality of the bone around implants. The increase in bone density improves the mechanical properties of the interface. The classification scheme for bone quality proposed by Lekholm et al. has since been accepted by clinicians and scientists as the standard criterion in evaluating patients for implant placement [2, 9-11]. Lekholm et al. suggested that jaws with favorable bone quality will allow for good stabilization of the implant fixture, poor bone quality give rise to instability of the fixture. Jaffin and Berman found that only 3\% of Brånemark system implants place in type 1,2 and 3 bone were lost after 5 years, while in type 4 bone, failure rates were $35 \%$ over the same period [10]. Several long-term clinical studies have similarly demonstrated that poor bone quality were accompanied with higher risk for implant failure.

Unfortunately, there have been insufficient studies focusing on the mechanical interrelations between the implant type (length) and bone quality. Literatures indicated that experimental approaches or clinical observations could not provide enough information to determine the biomechanics for complicated multi-parameter investigation. While the finite element (FE) method could provides mechanical responses and alters the parameters in a more controllable manner and has become a commonly used analytical tool in dental biomechanical studies [12-16]. Nevertheless, ambiguous simulated results usually confused as a result of unrealistic interfacial fixation assumptions between the different materials/components $[13,16]$. Therefore, non-linear FE analysis with reasonable interface conditions (contact) that could simulate the inherent flexibility within the implant system were needed for calculating detail mechanical characteristics for implant system and surrounding bone [16-18] Accordingly, the aim of this study was to verify the hypothesis that bone mechanical response are influenced by implant length, as well as bone quality using nonlinear FE stress analysis.

\section{METHODS}

\subsection{FE Models of Different Implant System}

Two different Frialit-2 root-form implant systems, $8 \mathrm{~mm}$ and $13 \mathrm{~mm}$ in fixture length with the same diameter $(4.5 \mathrm{~mm})$ and screw-retained $\mathrm{MH}-6$ abutment were selected as the investigated samples. The implant systems were embedded into a prepared machine cube with epoxy resin and sliced to expose the implant-resin section using a slicer (Isomet, Buehler, Illinois, USA) to measure the detailed inner dimensions of the components through image scanning using a flatbed scanner. For the FE models generation, the implant fixture was placed in a simplified jaw segment, a canaellous core surrounded by a $1.5 \mathrm{~mm}$ thick cortical layer was designed around the implant. The overall dimensions of the simulated bone block were $24 \mathrm{~mm}$ in height, $15 \mathrm{~mm}$ in mesiodistal length, and $12 \mathrm{~mm}$ in buccolingual width. Solid models of implant system, cortical and cancellous bone were constructed in a FE package (ANSYS v5.6, Swanson Analysis Inc., Houston, PA. U. S. A.) firstly. Free mesh approach provided in package with 4-node tetrahedral element (solid 72) were adopted to generate the FE model mesh pattern according to the geometry characteristics for the implant system and alveolar bone. In order to simulate the compensative mechanism within the implant system more realistically, the interfacial contact fixations were modeled to simulate the adaptation between various components (abutment/implant, abutment screw/abutment and abutment screw/implant). The contact element (contact 174 , defined as surface to surface) was one of the nonlinear structural analyses provided in ANSYS. The magnitude of the relative micro-motions and compressive stress-transfer could be obtained directly from the contact simulation problems. The FE models consisted of 23622, 26887 tetrahedral elements, 1424, 
1352 contact elements and 5961, 6502 nodes for fixture length $8 \mathrm{~mm}$ and $13 \mathrm{~mm}$ systems, respectively (Figure 1). The exterior nodes at the mesial and distal surfaces of the alveolar bone in the FE models were fixed in all directions as the boundary conditions.

\subsection{Simulated Material Properties and Occlusal Forces}

All materials used in the models were considered to be isotropic, homogeneous, and a linearly elastic. Elastic moduli of $110 \mathrm{GPa}$ and $14.8 \mathrm{GPa}$ and Possion' $\mathrm{s}$ ratio of 0.35 and 0.3 were used for titanium implant and cortical bone, respectively $[9,16]$. The values of elastic modulus for 4 types cancellous bone were chose from the results found by Rho et al., who measured elastic modulus of bone with different apparent densities. The elastic modulus of type 1 to 4 cancellous bone were $9.5 \mathrm{GPa}, 5.5 \mathrm{GPa}, 1.6 \mathrm{GPa}$ and $0.69 \mathrm{GPa}$, Possion' $\mathrm{s}$ ratio of the 4 types bone was 0.3 . Forces of $100 \mathrm{~N}$ were applied axially and buccolingually at the top nodes of the abutment as the loading conditions for all simulated model. There were 16 non-linear FE models with two implant fixture lengths $(8 \mathrm{~mm}$ and $13 \mathrm{~mm}$ ), four cancellous bone types and two occlusal forces simulated in this study.

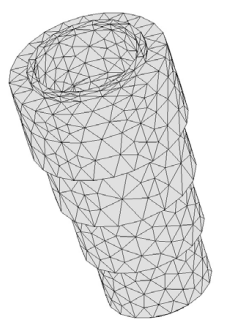

(a)

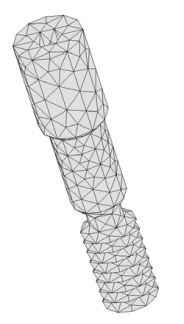

(d)

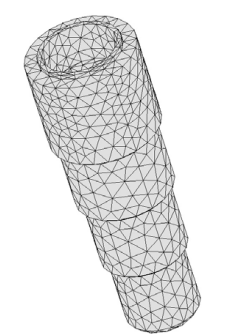

(b)

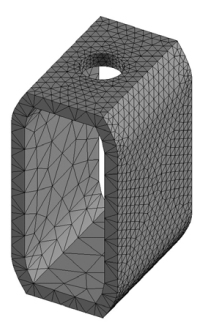

(e)

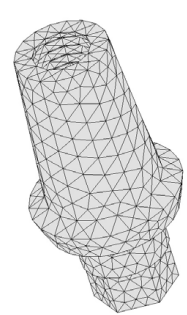

(c)

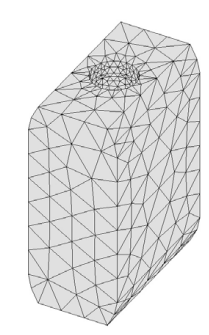

(f)
Fig. 1. A 3D FE model of an implant/bone system constructed for analysis in this study. (a) $8 \mathrm{~mm}$ fixture, (b) $13 \mathrm{~mm}$ fixture, (c) abutment, (d) abutment screw, (e) cortical bone shell and (f) cancellous bone block.

\section{RESULTS}

The maximal von Mises strain values in the cortical and cancellous bone are shown in Figures 2 and 3 . The results indicated that the maximum strain values of cortical and cancellous bone increased with lower bone density regardless of different implant length and loading conditions. The distributions of maximum strains were found near implant neck for high-density (type 1 and 2) bone under axial and lateral loadings and low-density (type 3 and 4 ) bone under lateral loading (Figure 4). However, they were observed around the implant base for low-density (type 3 and 4) bone under axial loading (Figure 5). The differences of cortical bone strains between $13 \mathrm{~mm}$ and $8 \mathrm{~mm}$ long implants were not significantly for different bone quality under occlusal loadings (axial and lateral). The highest strain of cancellous bone, about $5000 \mu \varepsilon$ was observed for short implant with lateral occlusal loading (Figure 3). Otherwise, lateral occlusal forces significantly increased the bone strain values when compared with axial occlusal forces regardless of the implant lengths and bone qualities. The maximum bone strains for lateral loading profoundly increased more than 3 and 1.5 times that of axial loading for cortical and cancellous bone, respectively (Figures 2 and 3). Furthermore, the maximum von-Mises stress of the implant system for lateral loading dramatically increased more than 6.5 times that of axial loading regardless of different implant length and bone qualities (Figure 6). The variations of stress values were not significantly between different implant lengths for axial loading, however, $13 \mathrm{~mm}$ long implant received higher stress values when compared to $8 \mathrm{~mm}$ system for lateral loading. Bone quality was found as the minor factor in which could not influence the

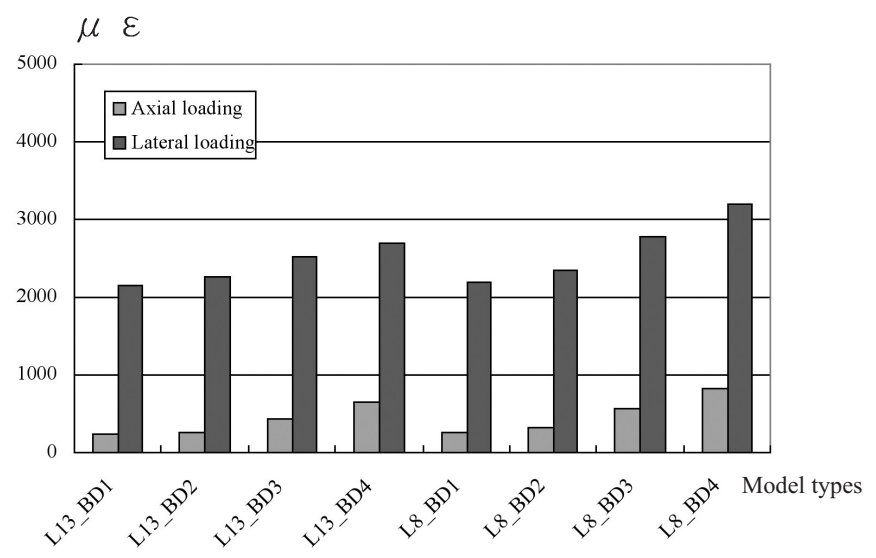

Fig. 2. Maximum von-Mises strains in cortical bone in all the models under axial and lateral loadings. 


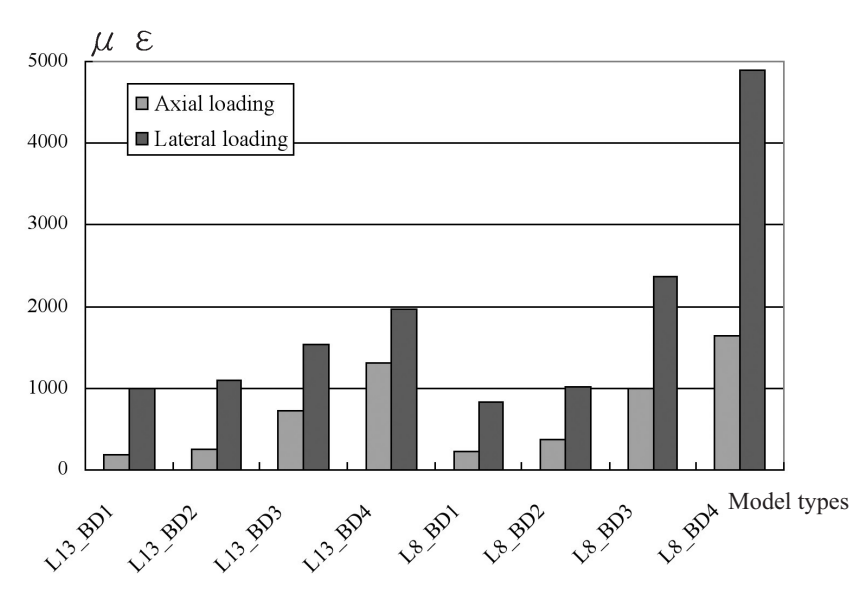

Fig. 3. Maximum von-Mises strains in cancellous bone in all the models under axial and lateral loadings.

implant stress patterns significantly.

\section{DISCUSSION}

Clinical studies and animal experiments have shown that marginal bone loss around implants that may lead to implant failure was associated in many cases with unfavorable loading conditions $[2,5-6,19]$. Unsuitable loading causes excessive stress/strain in the bone around the implant and may result in bone resorption. Consequently, it is valuable to investigate the mechanical responses in bone and their relation to different parameters of implant and bone. However, the biomechanical aspects are difficult to evaluate using clinical observation/experimental approaches with limited information and sample variations. Therefore, finite element analysis has generally been accepted as a complementary tool for understanding the detailed mechanical responses for many biologic investigations. The accuracy of an FEA is dependent on the numerical convergence and correctness of the assumptions imposed on the models simulating real physical conditions, i.e., the boundary conditions, interfacial conditions, etc. This study employed the non-linear contact FEA to mimic a flexible implant system and calculate the mechanical interactions of implant length, as well as bone quality, on stress in bone and implant.

The simulated results indicated that loading condition was the most important factor than bone qualities and implant lengths affecting the biomechanical aspects for alveolar bone and implant systems. Lateral occlusal forces produced a lateral bending moment that significantly increased the bony strain and implant stress values when compared with axial occlusal regardless of different bone qualities and implant lengths. Potential physiologic and engineering problems, such as osseointegration loss and screw loosening might increase easily with long-term unfavorable lateral occlusal forces. For the influences of the bone quality, because of the dense bone existed a higher modulus of elastic than low-density bone and was stronger and more resistant to deformation. The distributions of maximum strains were found near implant neck for high-density (type 1 and 2) bone under axial and lateral loadings and low-density (type 3 and 4) bone under lateral loading (Figure 4). Furthermore, the low-density bone was weaker and less resistant to deformation than in any of the other configurations, this was the reason that maximum strains found around the implant base for low-density bone (type 3 and 4 ) under axial loading (Figure 5). For the influences of the implant lengths, the variations of cortical bony strains between $13 \mathrm{~mm}$ and $8 \mathrm{~mm}$ long implants were not significantly as a results of the same contact areas between implant fixture and cortical bone were found for different implant lengths. However, highest cancellous bony strains were observed for short implant because of the load were transmitted from smaller contact areas between implant fixture and cancellous bone. Consequently, from all the simulated results implied that further understanding of the role of occlusal adjustment influencing the loading directions will as the important issue and might affect the longterm success of an implant system.

There were some limitations in this study, such as the loading conditions (axial and lateral) simulated in this study were not realistic and approximated only



Fig. 4. von Mises strain distribution of the alveolar bone with $13 \mathrm{~mm}$ implant and cancellous bone type 1 under lateral loading. The maximum strains were found near implant neck in the cortical bone. 


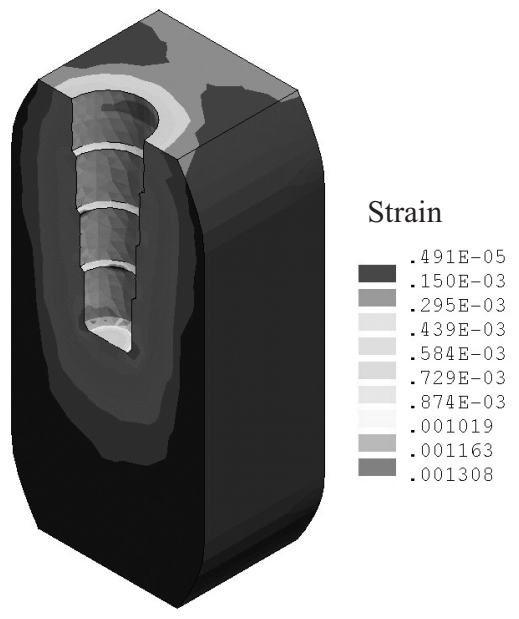

Fig. 5. von Mises strain distribution of the alveolar bone with $13 \mathrm{~mm}$ implant and with cancellous bone type 4 under axial loading. The maximum strains were found around implant base in the cancellous bone.

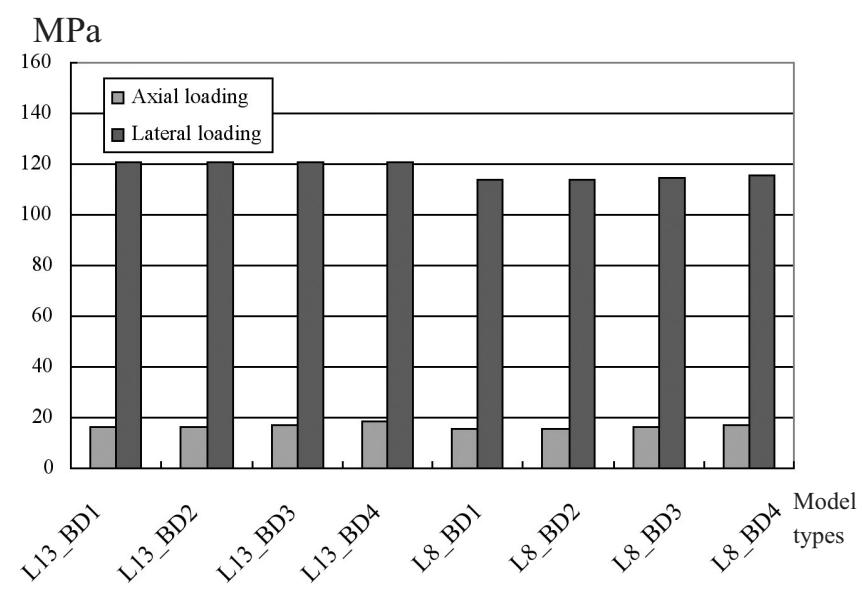

Fig. 6. Maximum von-Mises stresses at implant system in all the models under axial and lateral loadings.

roughly the complex balance between masticatory forces and their reactions. In addition, simulation of the whole mandibular body is very elaborate, smaller models have been proposed for parameter studies [20]. In this study, a segment of bone length of $7.5 \mathrm{~mm}$ of the mesial and distal sides was modeled in an attempt to approximate the posterior region of the mandible as a result of Teixeira et al. indicated that $4.2 \mathrm{~mm}$ mesiodistal length of a mandibular segment was accepted for FEA [21]. Therefore, the results from limitations of the modeling procedure and thus give only a general insight into tendencies of stress/stains variations under average conditions, without attempting to simulate individual clinical situations. The mechanical responses obtained from all simulations were the first approximation and must be validated with clinical trials.

\section{REFERENCES}

1. Sahin S, Cehreli MC, Yalcin E. The influence of functional forces on the biomechanics of implantsupported proethses-a review. J Dent 2002; 30: 271282.

2. Tada S, Stegaroiu R, Kitamurs E, Miyakawa O, Kusakari H. Influence of implant design and bone quality on stress/strain distribution in bone around implants: a 3-dimensional finite element analysis. Int J Oral Maxillofac Implants 2003; 18: 357-368.

3. Lindquist LW, Carlsson GE, Jemt T. A prospective 15-year follow-up study of mandibular fixed prostheses supported by osseointergrated implant. Clinical results and marginal bone loss. Clin Oral Implants Res 1996; 7: 329-336.

4. Lindquist LW, Rockler B, Carlsson GE. Bone resorption around fixtures in edentulous patients treated with mandibular fixed tissue-integrated prostheses. J Prosthet Dent 1988; 59: 59-63.

5. Block MS, Gardiner D, Kent JN, Misiek DJ, finger IM, GuerraL. Hydroxyapatite-coated cylindrical implants in the posterior mandible: 10-year observations. Int J Oral Maxillofac Implants 1996; 11: 626-633.

6. Isidor F. Loss of osseointergrated caused by occlusal load of oral implants. A clinical and radiographic study in monkeys. Clin Oral Implants Res 1996; 7: 143-152.

7. Albrektsson T, Johansson CB, Sennerby L. Biological aspects of implant dentistry: Osseointergration. Periodontol 2000 1994; 4:58-73.

8. Rieger MR, Adams WK, Kinzel GL. A finite element survey of eleven endosseous implants. J Prosthet Dent 1990; 63:457-465.

9. Holmes DC, Loftus JT. Influence of bone quality on stress distribution for endosseous implants. J Oral Implantology, 1997; 23: 104-111.

10. Lekholm U, Zarb GA. Patient selection and preparation. In: Branemark PI, Zarb GA, Alnrektsson $\mathrm{T}$, editors. Tissue-integrated prostheses: osseointergration in clinical dentistry. Chicago (IL): Quintessence Publishing, 199-209.

11. Rho JY, Ashman RB, Turner CH. Young's modulus of trabecular and cortical bone material: Ultrasonic and microtensile measurements. J Biomechanics 1993; 26: 111-119.

12. Lin CL, Chang CH, Cheng CS, Wang CH, Lee HE. Automated finite element mesh generation for maxillary second premolar. Comput Methods 
Programs Biomed 1999; 59: 187-195.

13. Lin CL, Chang CH, Ko CC. Multifactorial Analysis of An MOD Restored Human Premolar Using Auto-Mesh Finite Element Approach. J Oral Rehabil 2001; 28: 576-585.

14. Ko CC, Chu CS, Chung KH, Lee MC. Effect of posts on dentin stress distribution in pulpless teeth. J Prosthet Dent 1992; 67: 421-427.

15. Versluis A, Tantbirojn D, Douglas WH. Why do shear bond tests pull out dentin?. J Dent Res 1997; 6: 1298-1307.

16. Lin CL, Wang JC. Nonlinear finite element analysis of a splinted implant with various connectors and occlusal forces. Int J Oral Maxillofac Implants 2003; 18: 331-340.

17. Merz BR, Hunenbart S, Belser UC. Mechanics of the implant-abutment connection: an 8-degree taper compared to a butt joint connection. Int $\mathrm{J}$ Oral
Maxillofac Implants 2000; 15; 519-526.

18. Iplikcioglu H, Akca K, Cehreli MC, Sahin S. Comparison of non-linear finite element stress analysis with in vitro strain gauge measurements on a Morse taper implant. Int J Oral Maxillofac Implants 2003; 18: 258-265.

19. Hoshaw SJ, Brunski JB, Cochran GVB. Mechanical loading of Branemark implants affects interfacial bone modeling and remodeling. Int $\mathrm{J}$ Oral Maxillofac Implants 1994; 9: 345-360.

20. Meijer HJA, Starmans FJM, Bosman F, Steen WHA. A comparison of three finite element models of an edentulous mandible provided with implants. J Oral Rehabil 1993; 20: 147-157.

21. Teixeira ER, Sato Y, Akagawa y, Shindoi N. A comparative evaluation of mandibular finite element models with different lengths and elements for implant biomechanics. 1998; 25: 299-303. 